\title{
Revisão Taxonômica de Algumas Espécies de Ravenelia em Leguminosas do Cerrado Brasileiro
}

\author{
Denise V. Rezende ${ }^{1}$ \& José C. Dianese \\ ${ }^{1}$ Departamento de Fitopatologia, Instituto de Ciências Biológicas, Universidade de Brasília, \\ CEP 70919-900, Brasília, DF, Brasil, e-mail: santiago@unb.br
}

(Aceito para publicação em 26/07/2002)

Autor para correspondência: Denise Vilela de Rezende Santiago

REZENDE, D.V. \& DIANESE, J.C. Revisão taxonômica de algumas espécies de Ravenelia em plantas leguminosas do Cerrado brasileiro. Fitopatologia Brasileira 27:027-036. 2003.

\section{RESUMO}

Oito espécies de Ravenelia descritas anteriormente foram revisadas e acrescentadas ilustrações inéditas das características morfológicas de alguns desses fungos causadores de ferrugem em Leguminosae. As espécies de Ravenelia estudadas foram: Ravenelia bezerrae sobre Enterolobium ellipticum ; $R$. densifera sobre Senna silvestris; $R$. dieteliana sobre Calliandra dysantha. var. dysantha;
R. geminipora sobre Platymenia reticulata; $R$. lonchocarpi sobre Lonchocarpus campestris; $R$. mimosae-sensitivae sobre Mimosa radula var. imbricata; $R$. pileolarioides sobre Caesalpinia pyramydales e $R$. santos-costae, sobre Calliandra dysantha.

Palavras-chave adicionais: ferrugens neotropicais, taxonomia, Ravenelia.

\section{ABSTRACT}

Taxonomic review of some Ravenelia species on leguminous plants from the Brazilian Cerrado

Eight previously des cribed species of Ravenelia were reviewed and additional inedited illustrations from the following species were included. Ravenelia bezerrae on Enterolobium ellipticum; $R$. densifera on Senna silvestris; $R$. dieteliana on Calliandra dysantha var. dysantha; $R$. geminipora on Platymenia reticulata; $R$. lonchocarpi on Lonchocarpus campestris; $R$. mimosae-sensitivae on Mimosa radula var. imbricata; $R$. pileolarioides on Caesalpinia pyramydalis and $R$.. santos-costae on Calliandra dysantha.

\section{INTRODUÇÃO}

As espécies do gênero Ravenelia infetam plantas da família Leguminosae. Embora a maioria das descrições destas espécies tenha sido feita a muito tempo, muitas delas nunca foram ilustradas e carecem até mesmo de medições mais precisas de seus esporos e estruturas, além de não terem sido fornecidas as descrições e identificações precisas dos hospedeiros. Assim, visando complementar a descrição das espécies de Ravenelia do Cerrado brasileiro, oito espécies depositadas na Coleção Micológica de Referência da Universidade de Brasília (CMRUnB), foram estudadas detalhadamente. Com isto, descrições antigas e imprecisas foram atualizadas, não apenas usando-se microscopia ótica, mas também usando-se a tecnologia eficaz e atual da microscopia eletrônica de varredura.

\section{MATERIAL E MÉTODOS}

Os espécimes de Uredinales estudados foram identificados a partir de plantas naturalmente infetadas depositadas na (CMRUnB) e provenientes de Cerrado do Distrito Federal, Mato Grosso, Mato Grosso do Sul, Maranhão, Minas Gerais, Bahia, Espírito Santo e São Paulo. A identificação das plantas hospedeiras foi feita nos herbários do Departamento de
Botânica da Universidade de Brasília e da Reserva Biológica do IBGE com o apoio da Prof ${ }^{a}$. Carolyne Proença e da Dra. Roberta C. Mendonça, respectivamente.

A análise taxonômica dos fungos causadores de ferrugem envolveu cortes de material vegetal em micrótomo de congelamento marca Micron HM505E, seguido de montagem semipermanente em lâminas e observação em microscópio ótico. Cortes histológicos de partes de plantas infetadas com Uredinales foram feitos em micrótomo de congelamento, com temperatura regulada para -20 a $-21^{\circ} \mathrm{C}$. Materiais secos foram previamente colocados em solução hidratante aquosa ( $10 \%$ etanol, e $0,1 \%$ Tween-20) onde permaneceram por $24 \mathrm{~h}$ antes de serem congelados e cortados. Os cortes selecionados em gotas sobre lâminas foram transferidos para outras lâminas onde adicionaram-se gotas do corante lactoglicerol-azul de algodão ou solução de cloral hidratado, quando se pretendia ver poros germinativos dos esporos. Para a observação de detalhes morfológicos ou ontogênicos dos esporos, utilizou-se o corante de Bruzesse \& Hassan (1983) sem fenol, ou seja, com a seguinte composição: $40 \mathrm{~g}$ de cloral hidratado, $15 \mathrm{ml}$ de clorofórmio, $125 \mathrm{ml}$ de ácido lático a 90\%, $300 \mathrm{ml}$ de etanol $95 \%$ e $0,6 \mathrm{~g}$ de azul de anilina. Em seguida, as lâminas foram seladas com esmalte de unha, etiquetadas e armazenadas para estudo. As observações e fotografias foram feitas em fotomicroscópio 
Zeiss-Axiophot E (Carl Zeiss Oberkachen, Alemanha).

Para o exame microscópico da superfície de tecidos infetados feitos em microscópio eletrônico de varredura (MEV), foram cortados fragmentos frescos ou hidratados de tecidos medindo $0,5 \times 0,8 \mathrm{~cm}$, que posteriormente foram transferidos para recipientes com solução fixadora de glutaraldeído a $3 \%$ em tampão cacodilato de sódio $0,05 \mathrm{M}$, $\mathrm{pH}$ 6,9. Os recipientes foram tampados e deixados em geladeira a $4{ }^{\circ} \mathrm{C}$ por $12 \mathrm{~h}$. Em seguida, efetuaram-se cinco lavagens sucessivas do material com a mesma solução tampão. Após a lavagem as peças foram tratadas com tetróxido de ósmio (OsO4) a $1 \%$ no mesmo tampão de cacodilato permanecendo em refrigerador a $4{ }^{\circ} \mathrm{C}$ por $4 \mathrm{~h}$. Posteriormente, cinco lavagens consecutivas foram feitas novamente com a solução tampão (Souza, 1998).

O material foi desidratado em uma série aquosa contendo $30 \%, 50 \%, 70 \%, 85 \%, 95 \%$ e $100 \%$ de acetona. Os fragmentos permaneceram em cada concentração por $10 \mathrm{a}$ 20 min, sendo que a última solução foi trocada três vezes. Em seguida, foi feita a secagem do material ao ponto crítico em um aparelho de secagem CPD-030 Balzers (Baltec, Fuerstentum, Liechtenstein) utilizando-se CO2 líquido. Os fragmentos de tecidos secos foram colados sobre suportes metálicos com pasta condutiva de prata. Os suportes contendo o material foram então cobertos com ouro por meio de pulverização catódica em aparelho marca Balzers, modelo SCD50 por $140 \mathrm{~s}$. Observações foram feitas em microscópio eletrônico de varredura marca Jeol, modelo JSM840-A (Jeol Ltd., Tóquio, Japão) com acelerações de 5 e $10 \mathrm{KV}$ e distância de trabalho de $20 \mathrm{~mm}$ com obtenção de fotografias de várias estruturas e esporos dos fungos. A base para identificação das espécies incluiu estudos de espessura da parede e ornamentação, cor, tamanho e forma dos teliósporos e urediniósporos, características dos pedicelos dos teliósporos e o número e posição dos poros germinativos em urediniósporos. Paráfises, formas dos esporos, sintomas no hospedeiro ou sinais, especificidade do hospedeiro foram características adicionais que também ajudaram na identificação das espécies.

Entre as espécies aqui descritas Ravenelia densifera Henn. \& Cumm., R. dieteliana P. Henn., R. geminipora Henn. $\&$ Cumm., R. lonchocarpi Lager \& Diet. e R. pileolarioides H. Syd. \& P. Syd. foram ilustradas pela primeira vez, tiveram seus hospedeiros identificados ao nível de espécie e foram acrescentadas ou complementadas várias características morfológicas de estruturas e esporos desses Uredinales.

\section{RESULTADOS E DISCUSSÃO}

1. Ravenelia bezerrae Dianese, Med. \& Furlan. Fitopat. Bras. 18:442. 1993. (Figura 1)

Espermogônios e écios não-vistos. Urédios (392-) 568 (-735) x (245-) 308 (-441) $\mu \mathrm{m}$, anfígenos, maioria epífilo, às vezes mistos, subepidérmicos, irrompentes, marrom-claros, parafisados. Paráfises cilíndricas ou clavadas, himeniais, com ápices alargados medindo $24-35 \times 2-3 \mu \mathrm{m}$, agrupadas ao redor dos urediniósporos. Urediniósporos (24-) 25 (-26) x (15-) 17 (-18) $\mu \mathrm{m}$, equinulados, elipsóides a obovóides, base truncada, parede $3-5 \mu \mathrm{m}$ de espessura, dois - quatro poros germinativos. Télios (490-) 700 (-882) x (245-) 304 (-392) $\mu \mathrm{m}$, anfígenos, maioria epífilo, subepidérmicos, irrompentes, marrom-escuros a negros. Teliósporos compostos, multicelulares (69-) 75 (-82) x (65-) $70(-78) \mu \mathrm{m}$, ornamentados, tuberculares, marrom-escuros a negros, quatro células centrais (27-) $29(-31) \times(18-) 21(-27) \mu \mathrm{m}$, oito células marginais, (31-) $36(-42) \times(22-) 25(-30) \mu \mathrm{m}$, tuberculares Cistos aderentes, (20-) 21 (-23) x (9-) $11(-12) \mu \mathrm{m}$, em número de oito. Pedicelo, $27 \mu \mathrm{m}$, persistente, composto por cinco filamentos hifálicos soldados.

Espécimes examinados: em folhas vivas de Enterolobium ellipticum Benth.: Estrada Brasília-PADF, 300 metros após o trevo, próximo à Papuda, Brasília, DF, 03/VI/ 1993, J.C. Dianese 792, UB 3580; Estação Ecológica das Águas Emendadas, Planaltina, DF, 06/I/1998, M. Sanchez 3151, UB 15909.

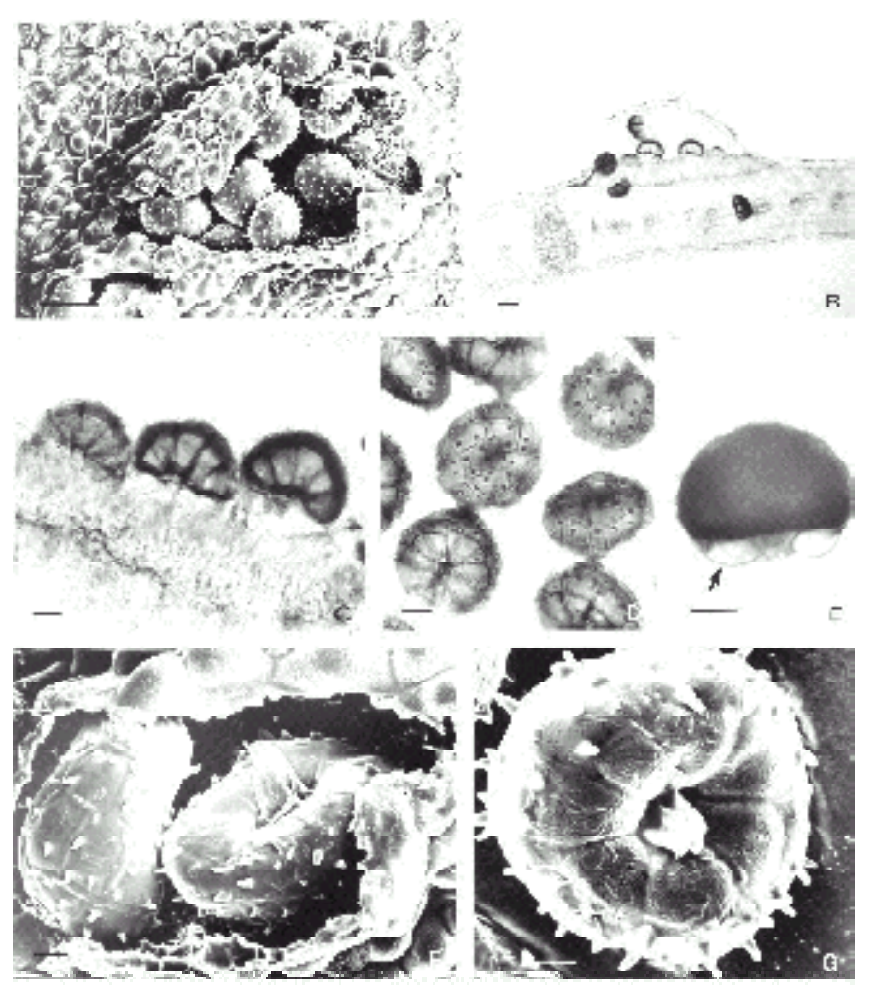

FIG. 1 - A - G. Ravenelia bezerrae sobre Enterolobium ellipticum. A - Télio irrompente visto ao MEV. B - Corte transversal de télio visto ao MO mostrando teliósporos e enfatizando condição subepidérmica do télio. $C$ - Corte transversal de télio ao MO contendo três teliósporos. D Teliósporos vistos ao MO com ornamentações tuberculares. E - Teliósporos ao MO com cistos aderentes (seta) e pedicelo composto. F e G Teliósporos compostos tuberculares vistos ao MEV. Barras: $\mathbf{A}=70 \mu \mathrm{m} ; \mathbf{B}=\mathbf{6 0} \mu \mathrm{m} ; \mathbf{C}, \mathbf{D}$ e $\mathbf{E}=$ $20 \mu \mathrm{m} ; \mathbf{F}$ e $\mathbf{G}=\mathbf{1 0} \mu \mathrm{m}$. 
Apenas duas outras espécies de Ravenelia foram documentadas em Enterolobium:Ravenelia havanensis Arth. sobre Enterolobium cyclocarpon (Jacq.) Griseb. em Cuba e Costa Rica (Cummins, 1978) e R. hassleri Speg. $(=R$. dieteliana Henn.) (Lindquist, 1946). Ambas diferem de $R$. bezerrae em termos de dimensões de estruturas e esporos. Ravenelia havanensis causa galhas em pecíolos, onde há produção de espermogônios e écios, apresenta até cinco poros germinativos nos urediniósporos e tubérculos maiores nos teliósporos e, além disso, o número de células dos teliósporos é maior do que em $R$. bezerrae. Ravenelia hassleri tem urediniósporos com seis poros germinativos e dimensões diferentes além de formar teliósporos completamente lisos. A espécie foi descrita recentemente (Dianese et al., 1993), sendo aqui complementarmente ilustrada.

2. Ravenelia densifera Henn. \& Cumm. Rept. Tottori Mycol. Inst. (Japan) 28:3. 1990. (Figura 2)

Sinonímia: Uredo cassiicola P. Henn. Hedwigia 34:98. 1895.

Espermogônios e écios não-vistos. Urédios anfígenos, peridiados, maioria hipófilo, mistos, laranja-amarronzados, subcuticulares na origem, irrompentes, fortemente parafisados. Paráfises himeniais cilíndricas a clavadas. Urediniósporos (15-) 18 (-22) x (12-) $13(-15) \mu \mathrm{m}$, equinulados, obovóides a elipsóides, parede $1,5-2 \mu \mathrm{m}$, com quatro poros germinativos equatoriais unizonados; equinulações circundadas por linha clara em MEV. Télios anfígenos, associados aos urédios, subcuticulares, irrompentes. Teliósporos compostos, multicelulares, (60-) 87 (-107) $\mu \mathrm{m}$, diametralmente com cinco - sete células, marromdourados, 16 - 19 células centrais, (16-) 19 (-21) x (13-) 16 (-18) $\mu \mathrm{m}$, lisas quando jovens, tornando-se fortemente tuberculares como as células marginais, ornamentações às vezes cônicas, cilíndricas, bifurcadas ou com extremidades esféricas, medindo até $15 \mu \mathrm{m}$; células marginais (22-) 25 (27) $\mathrm{x}(18-) 21(-23) \mu \mathrm{m}$. Cistos aderentes, dificilmente vistos, em número variável (oito - dez). Pedicelos compostos, quatro - cinco hifas, até $35 \mu \mathrm{m}$ de comprimento.

Espécimes examinados: em folhas vivas de Senna silvestris (Veloso) Irwin \& Barneby (=Cassia silvestris Veloso): Goiatuba, GO, 28/V/1993, J.C. Dianese 878, UB 3897.

A espécie $R$. densifera foi descrita por Hennen \& Cummins (1990) em várias amostras de Senna silvestris encontradas no Brasil, algumas inclusive coletadas no Distrito Federal. Porém, os autores não apresentaram ilustrações do fungo e, além disso, a descrição original foi complementada neste trabalho.

Urédios e télios são anfígenos, principalmente hipófilos e não apenas epífilos, conforme Hennen \& Cummins (1990). Os urédios são mistos e, quando mais velhos, fortemente parafisados e com perídio. As paráfises, mencionadas por Hennen \& Cummins (1990), são periféricas, cilíndricas a clavadas, na mesma altura dos urediniósporos. As outras características aqui mostradas estão de acordo com aquelas descritas para Uredo cassiicola P. Henn. (Hennings, 1895). Os urediniósporos mostram, ao MEV, halos ao redor das equinulações, formando nervuras entre elas. Os télios são encontradas juntos aos urédios ou, às vezes, separados, mas com poucos teliósporos por télio. Discordando da descrição original, os teliósporos apresentam-se ornamentados, tanto nas células centrais quanto nas marginais, sendo os tubérculos facilmente observados nas células periféricas. Os tubérculos surgem à medida que o téliósporo envelhece, portanto, eles aparecem primeiro nas células periféricas, sendo pouco comum encontrar células lisas. Os cistos são aderentes, nãohigroscópicos, uniseriados em número variável (oito - dez). Os teliósporos têm pedicelos curtos e decíduos.
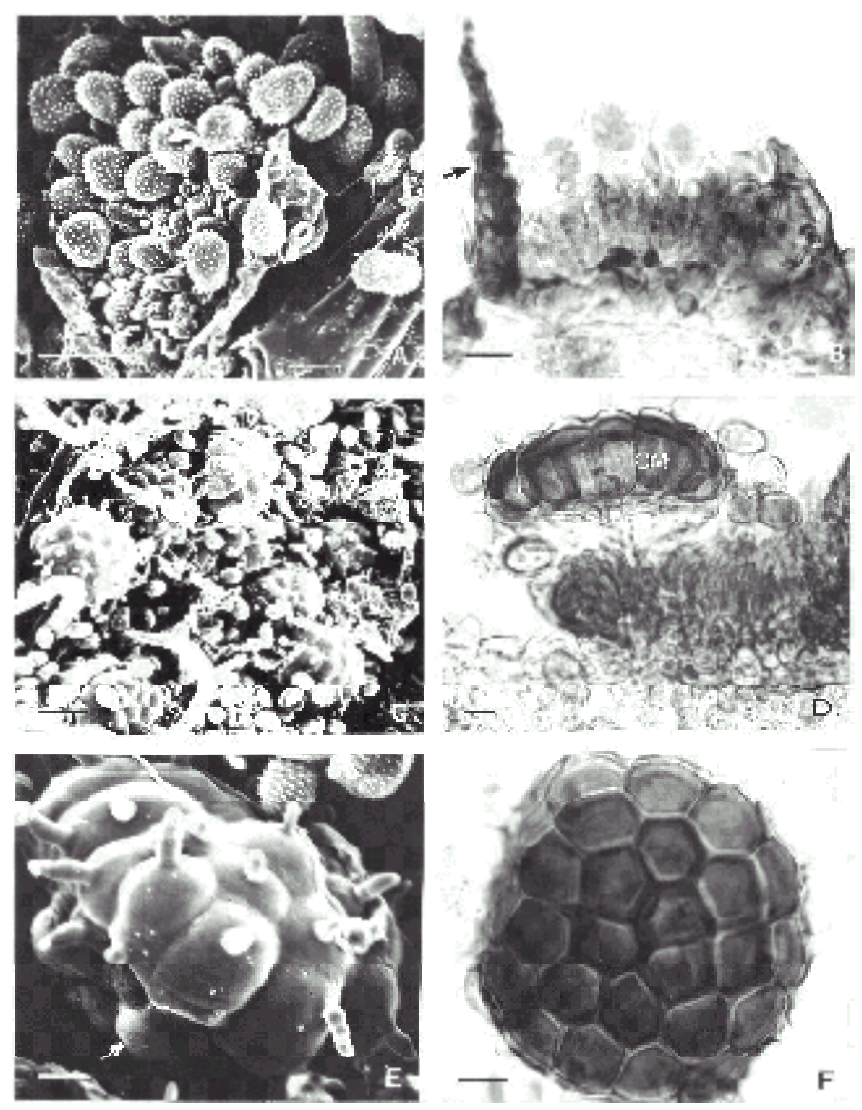

FIG. 2 - A - F. Ravenelia densifera sobre Senna silvestris. A - Urédio hipófilo visto ao MEV, mostrando paráfises (seta) e urediniósporos equinulados. B - Corte de urédio visto ao MO, mostrando perídio (seta) e urediniósporos com poros germinativos. C - Soro misto contendo teliósporos e urediniósporos vistos ao MEV. D - Corte de télios com teliósporos vistos ao MO, mostrando as unidades que constituem o esporo composto e células marginais. E - Teliósporo composto visto ao MEV, contendo células ornamentadas por tubérculos e cistos aderentes (seta). F - Teliósporo composto ao MO contendo 13 células centrais e 15 células marginais. Barra: $\mathbf{A}=\mathbf{1 5} \mu \mathrm{m} ; \mathbf{B}, \mathbf{D}, \mathbf{E}$ e $\mathbf{F}=\mathbf{1 0}$ $\mu \mathrm{m} ; \mathbf{C}=\mathbf{4 0} \mu \mathrm{m}$. 
3. Ravenelia dieteliana P. Henn. Hedwigia 34:96. 1895. (Figura 3)

Sinonímia: Ravenelia hassleri Speg. Anal. Mus. Nac. Hist. Nat.BuenosAires 23:21. 1912.

Espermogônios e écios não-vistos. Urédios (38-) 65 (-100) x (25-) 42 (-100) $\mu \mathrm{m}$, principalmente anfígenos, mistos, hipófilos, subepidérmicos na origem, marrom-claros, parafisados. Paráfises clavadas globóides a ovóides nos ápices, (56-) 64 (-69) $\mu \mathrm{m}$ de comprimento e (19-) 21 (-23) x (4-) 5 (-6) $\mu \mathrm{m}$ nos ápices. Urediniósporos (24-) $26(-28) \mathrm{x}$ (19-) 21 (-22) $\mu \mathrm{m}$, marrom-dourados, oblongos a ovóides, fortemente equinulados, parede $1,0-1,5 \mu \mathrm{m}$ de espessura, quatro - seis poros germinativos equatoriais ou dispersos. Télios (50-) 97 (-125) x (30-) 48 (-100) $\mu \mathrm{m}$, anfígenos, subepidérmicos, irrompentes, marrom-escuros, paráfises semelhantes aos do urédio. Teliósporos compostos, multicelulares, pedicelados, (40-) 45 (-50) x (40-) 43 (-47) $\mu \mathrm{m}$, quatro células centrais, (20-) 22 (-27) x (12-) 16 (-19)
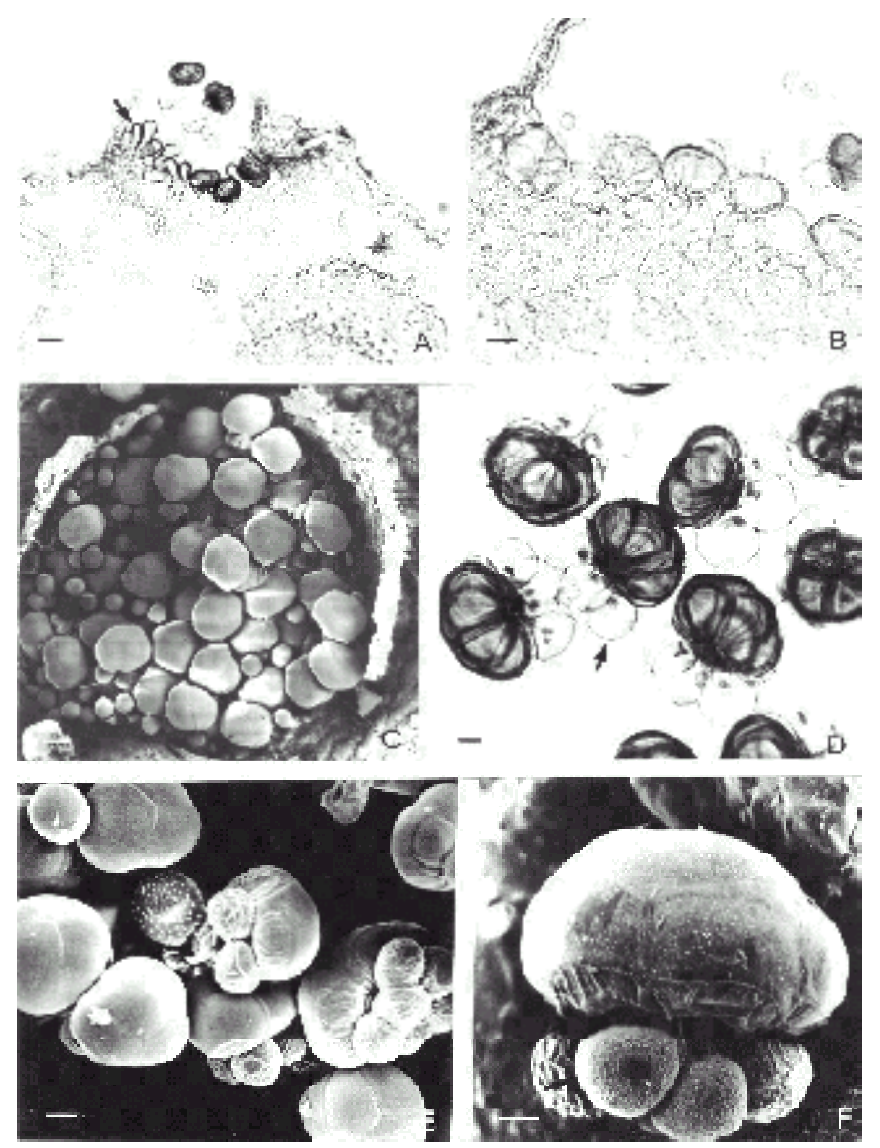

FIG. 3 - A - F. Ravenelia dieteliana sobre Calliandra dysantha var. dysantha. A e B - Cortes de télios subepidérmicos vistos ao MO, mostrando teliósporos e paráfises (seta). C - Télio visto ao MEV, mostrando teliósporos e paráfises himeniais. D Teliósporos vistos ao MO, mostrando cistos pendentes higroscópicos (seta). E e F - Teliósporos lisos vistos ao MEV com cistos. Barras: $A=30$ $\mu \mathrm{m} ; \mathrm{B}, \mathbf{C}$ e $\mathbf{E}=20 \mu \mathrm{m} ; \mathbf{D}=\mathbf{1 0} \mu \mathrm{m} ; \mathbf{F}=5 \mu \mathrm{m}$. $\mu \mathrm{m}$, lisas, parede $2-3 \mu \mathrm{m}$ de espessura; seis células marginais, (17-) 20 (-23) x (13-) 18 (-20) $\mu \mathrm{m}$, lisas, paredes $2-3 \mu \mathrm{m}$ de espessura. Cistos (18-) 20 (-20) x (17-) 19 (-20) $\mu \mathrm{m}$, aderentes, em número de quatro - seis, geralmente seis, globóides, higroscópicos; pedicelos decíduos com 3 a $10 \mu \mathrm{m}$.

Espécimes examinados: em folhas vivas de Calliandra dysantha Benth. var. dysantha: Estação Ecológica das Águas Emendadas, Planaltina, DF, 21/I/1997, M. Sanchez 2246, UB 13185; 21/III/1997, M. Sanchez 2455, UB 13787.

Comparando-se esta espécie de Ravenelia com outras descritas em Calliandra spp. no Brasil, observou-se que os dados encontrados correspondem àqueles relatados para $R$. dieteliana em Calliandra macrocephala Benth. Mais quatro espécies de Ravenelia foram relatadas em Calliandra. A primeira, $R$. parzchkeana Diet. infeta Calliandra sp. e apresenta urédios e télios epífilos, urediniósporos elipsóides, com quatro poros germinativos. Os seus teliósporos tuberculados e paráfises de ápices bem menores separam claramente esta espécie de $R$. dieteliana. Ravenelia affinis Syd., parasita de $C$. turbinata Benth., se diferencia principalmente pelo tamanho e número de células marginais do teliósporo, com nove células marginais grandes e nove cistos, enquanto que $R$. dieteliana tem seis células marginais e seis cistos (Sydow $\&$ Sydow, 1915). Ravenelia santos-costae Dianese; Med; Santos; Furlan; Sanchez \& A. C. Dianese apresenta urédios hipófilos e télios epífilos, teliósporos maiores e células centrais e marginais equinuladas e células marginais tuberculadas. A única semelhança com $R$. dieteliana seria o hospedeiro que também é $C$. dysantha, porém, trata-se de uma variedade diferente $C$. dysantha var. dysantha.

Outras espécies de Ravenelia foram descritas em plantas do gênero Calliandra fora do Brasil como: R. echinata Lager. \& Diet. em Calliandra spp. no Equador; Ravenelia linda Cumm. \& J.W. Baxt. em Calliandra tapirorum Standley, Honduras; R. mexicana Tranz. \& Diet. em C. grandiflora Benth. (C. anomala Benth.) México; R. affinis Syd. em Calliandra turbinata Benth. no Estado de Mato Grosso; $R$. ectypa Arth. \& Holway em C. laxa Benth. na Bolívia; $R$. lagerheiniana Dietel em Calliandra falcata Benth. no Equador (Sydow \& Sydow, 1915; Cummins, 1978). Ressaltase que todas essas espécies apresentam características que as diferenciam da espécie em estudo principalmente quanto ao tamanho dos teliósporos, presença de equinulações no teliósporo, ausência de paráfises, posição do soro, número de cistos e número de células marginais.

4. Ravenelia geminipora Henn. \& Cumm. Rept. Tottori Mycol. Inst. (Japan) 28:4. 1990. (Figuras 4-5)

Espermogônios e écios não-vistos. Urédios (12-) 35 (-62) x (12-) 24 (-38) $\mu \mathrm{m}$, epífilos, subepidérmicos, irrompentes, marrons, parafisados. Paráfises (57-) 93 (-120) x (3-) 4 (-4) $\mu \mathrm{m}$, himeniais e periféricas, laranja-ferrugíneas, cilíndricas a espatuladas, parede com $30 \mu \mathrm{m}$ de espessura no ápice. Urediniósporos (23-) 30 (-35) x (20-) 22 (-27) $\mu \mathrm{m}$, obovóides a elipsóides, equinulados, amarelados; parede 2 $4 \mu \mathrm{m}$ de espessura nas laterais e $5 \mu \mathrm{m}$ no ápice, com dois 
pares geminados de poros equatoriais unizonados. Télios epífilos, em fendas ao redor de urédios formando círculos, marrom-escuros a pretos, (38-) 70 (-125) x (12-) 32 (-50) $\mu \mathrm{m}$, subepidérmicos, irrompentes. Teliósporos compostos, (84-) 97 (-113) x (-77) 95 (-113) $\mu \mathrm{m}$, marrom-escuros, diametralmente com seis - oito células, lisos; 14 células centrais, (15-) 20 (-22) x (14-) 17 (-20) $\mu \mathrm{m}$, hexagonais; 14 células marginais, (20-) $22(-25) \times(12-) 16(-22) \mu \mathrm{m}$, lisas. Cistos (20-) 22 (-22) x (15-) 20 (-20) $\mu \mathrm{m}$, em número de 14, uniseriados. Pedicelos compostos, seis - oito hifas, hialinos, (12-) 25 (-30) x (12-) 15 (-17) $\mu \mathrm{m}$.

Espécimes examinados: em folhas vivas de Platymenia reticulata Benth.: BR 050, próximo ao Posto Mineirão, Araguarí, MG, 25/III/1993, M. Sanchez 27, UB 3524; Estação Ecológica Águas Emendadas, Planaltina, 05/III/1997, DF, M. Sanchez 2399, UB 13645.

Esta espécie foi coletada também em Minas Gerais, Bahia, São Paulo, Goiás e Mato Grosso, e foi descrita sem ilustraçôes (Hennen \& Cummins, 1990). Os dois pares gêmeos
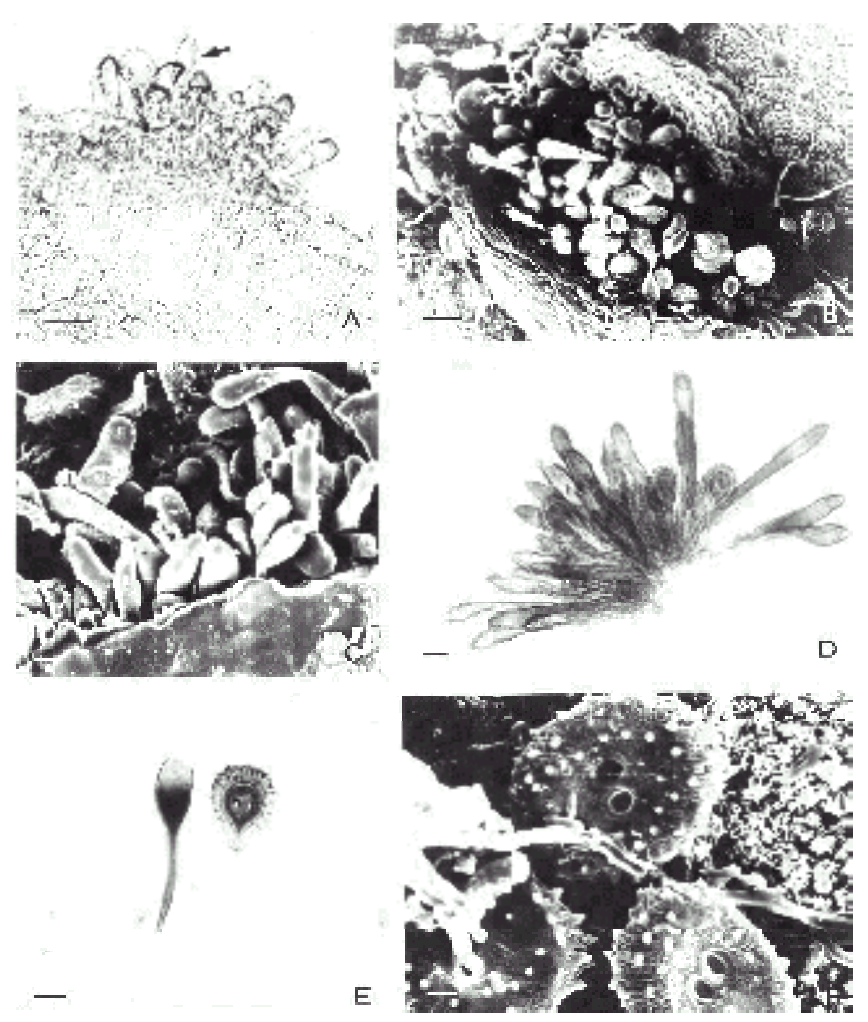

FIG. 4 - A - F. Ravenelia geminipora sobre Platymenia reticulata. A - Corte de urédio subepidérmico irrompente visto ao MO, mostrando paráfises (seta) e urediniósporos equinulados. B - Urédio visto ao MEV. C - Urédio com paráfises periféricas vistos ao MEV. D - Paráfises e urediniósporos vistos ao MO. E - Detalhe de paráfise e urediniósporo mostrando parede dupla e um par de poros germinativos. F - Urediniósporos e respectivos poros germinativos vistos ao MEV. Barras: $\mathbf{A}=$ $30 \mu \mathrm{m} ;$ B e D $=20 \mu \mathrm{m} ; \mathbf{C}$ e $\mathbf{E}=10 \mu \mathrm{m} ; \mathbf{F}=5 \mu \mathrm{m}$. de poros germinativos, um par de cada lado, nos urediniósporos, constituem uma importante característica para a identificação desta espécie, ora ilustrada pela primeira vez.

\section{Ravenelia lonchocarpi Lager. \& Diet. Hedwigia 33:46.} 1894. (Figuras 6-7)

Espermogônios e écios não vistos. Urédios hipófilos, subepidérmicos, irrompentes (98-) 102 (-108) x (69-) 81 (98) $\mu \mathrm{m}$, pequenos, marrom-claros, parafisados. Paráfises periféricas, (35-) 80 (-100) x (5-) $7(-8) \mu \mathrm{m}$, afiladas nos ápices, recurvadas sobre os esporos, formando uma cesta. Urediniósporos (24-) 30 (-32) x (16-) 18 (-20) $\mu \mathrm{m}$, geralmente reniformes, às vezes obovóides ou piriformes, paredes 1 $1,5 \mu \mathrm{m}$ de espessura; equinuladas na parte côncava e lisas na

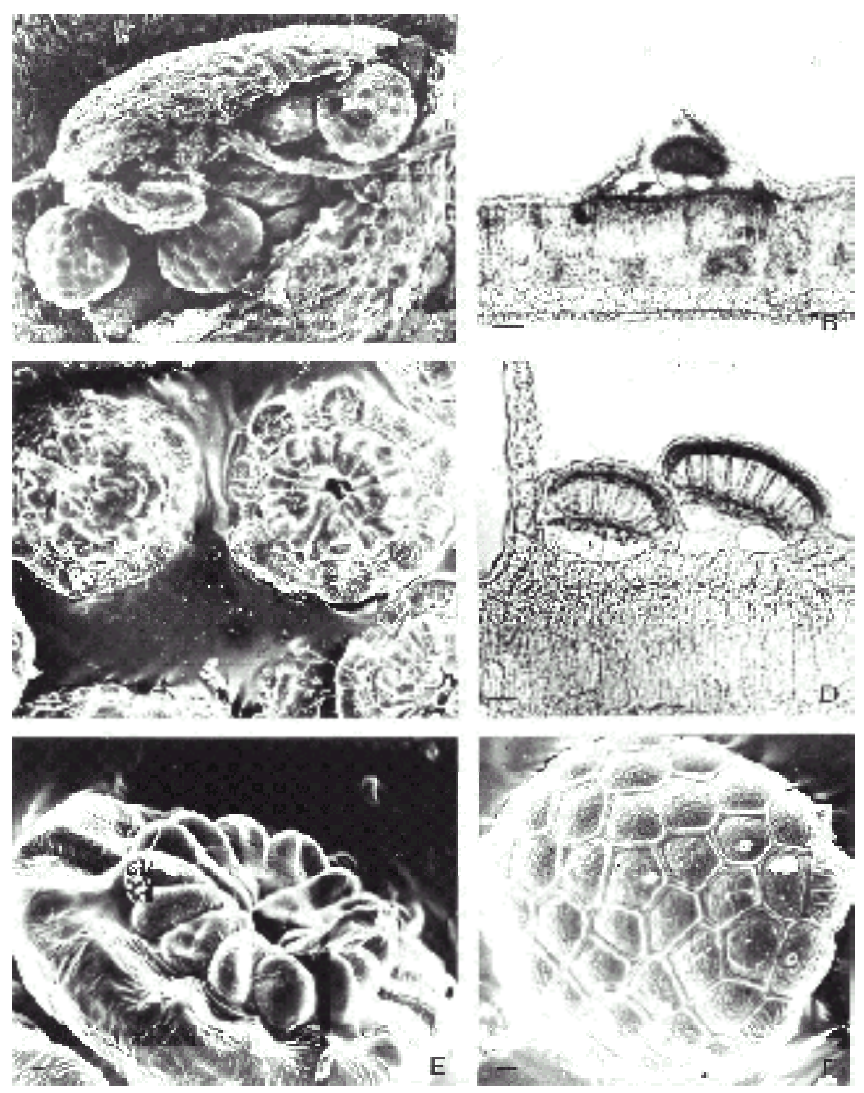

FIG. 5 - A - F. Ravenelia geminipora sobre Platymenia reticulata. A - Télio subepidérmico irrompente visto ao MEV. B - Corte de télio subepidérmico irrompente mostrando teliósporo composto e cistos aderentes (seta) ao MO. C - Face inferior do teliósporo composto mostrando células marginais, cistos aderentes e pedicelo (seta) ao MEV. D - Detalhe de corte transversal de télio com dois teliósporos compostos mostrando também cistos e pedicelo hifálico composto ao MO. E e F - Detalhes dos teliósporos compostos mostrando face inferior e superior, respectivamente ao MEV. Barras: $\mathbf{A}=\mathbf{2 0} \mu \mathrm{m} ; \mathbf{B}=\mathbf{3 0}$ $\mu \mathrm{m} ; \mathrm{C}$ e $\mathbf{D}=\mathbf{1 0} \mu \mathrm{m} ; \mathrm{E}$ e $\mathbf{F}=\mathbf{5} \mu \mathrm{m}$ 
parte convexa; dois - quatro poros germinativos, subequatoriais ou equatoriais. Télios hipófilos, subepidérmicos, irrompentes, parafisados. Teliósporos compostos, multicelulares, (50-) 75 (-92) x (32-) 60 (-72) $\mu \mathrm{m}$, marrons, com seis células dispostas ao longo de seu diâmetro, tuberculares, quatro - seis células centrais, (20-) 24 (-27) x (19-) 22 (-24) $\mu \mathrm{m}$; seis - oito células marginais, (25-) 26 (29) x (17-) 21 (-27) $\mu \mathrm{m}$, seis - dez tubérculos por célula; tubérculos $2-7 \mu \mathrm{m}$, cônicos ou arredondados, hialinos ou pigmentados. Cistos seis - oito, pendentes, globóides a ovóides, higroscópicos, 20 x $18 \mu \mathrm{m}$. Pedicelos hialinos, curtos, hifálicos, compostos e decíduos.

Espécimes examinados: em folhas vivas de Lonchocarpus campestris Mart.: $60 \mathrm{~km}$ ao norte de Balsas e $17 \mathrm{~km}$ a norte de Fortaleza dos Nogueiras, MA, 11/IV/1995,
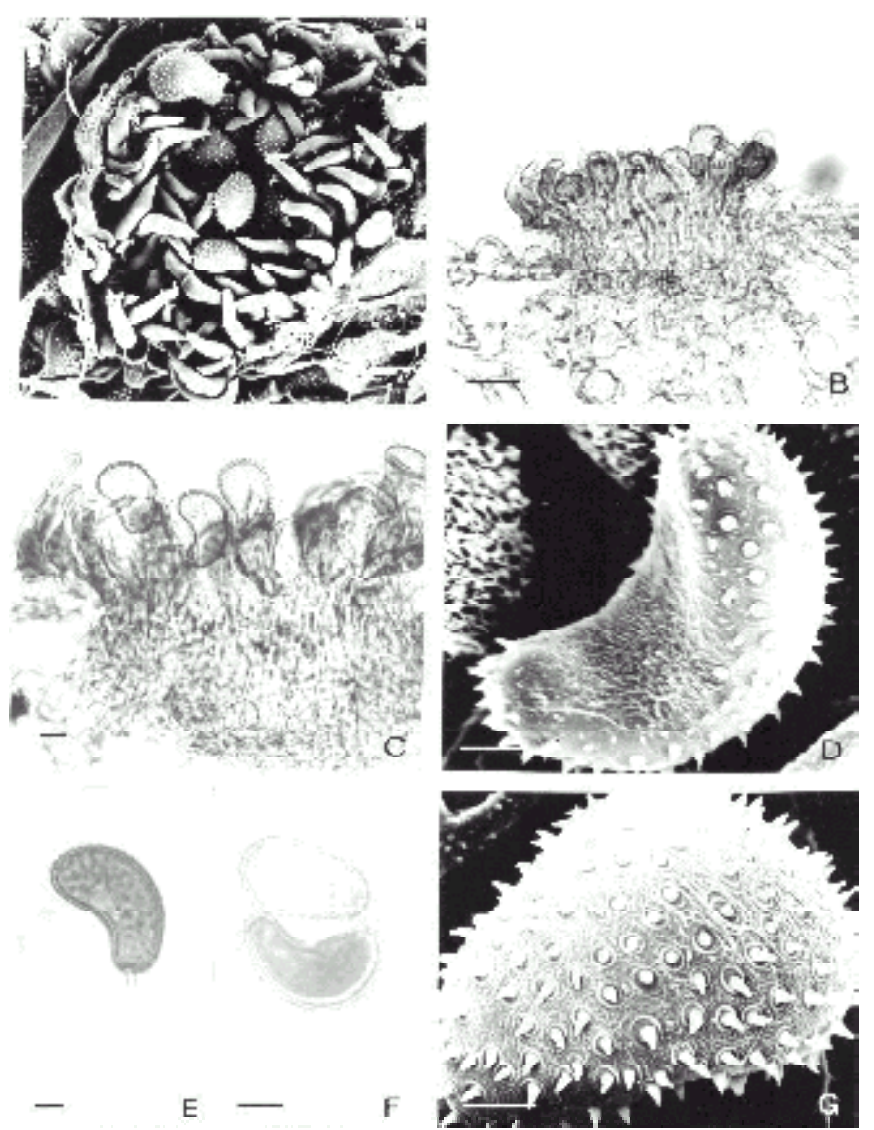

FIG. 6 - A - G. Ravenelia lonchocarpi sobre Lonchocarpus campestris. A - Urédio subepidérmico visto ao MEV, mostrando paráfises curvadas, a maioria periférica e urediniósporos equinulados. B e C Cortes de urédios vistos ao MO, mostrando paráfises e urediniósporos reniformes. D Urediniósporo reniforme, equinulado no dorso e liso na área convexa visto ao MEV. E e F Urediniósporos vistos ao MO. G - Urediniósporo vistos em MEV mostrando nervuras e halos ao redor das equinulações. Barras: $A, C$ e $F=10$ $\mu \mathrm{m} ; \mathbf{B}=20 \mu \mathrm{m} ; \mathbf{D}, \mathbf{E}$ e $\mathbf{G}=5 \mu \mathrm{m}$.
M. Sanchez 626, UB 7960; $64 \mathrm{~km}$ ao sul do centro de Imperatriz, MA, 14/IV/1995, J.C. Dianese 2197, UB 8165.

A espécie $R$. lonchocarpi foi relatada em $L$. campestris por Lagerheim \& Dietel (Dietel, 1894); em Lonchocarpus sp. por Jackson (1931); em L. latifolius HBK por Silveira (1951) e em L. nitidus Benth. por Lindquist \& Costa Neto (1963), sendo todas as amostras coletadas no Brasil. Baxter (1968) fez uma revisão das espécies de Ravenelia ocorrendo em Lonchocarpus spp., e com isso examinou os aspectos nomenclaturais acrescentando detalhes morfológicos confirmados no presente estudo. De acordo com Baxter (1968), a descrição do urédio de $R$. lonchocarpi feita por Arthur (1925), baseou-se no estádio uredinial de Puccinia nephroidea Syd. Os dois urédios diferem quanto à base dos urediniósporos, mas as paráfises de $P$. nephroidea são de paredes relativamente finas, redondas nos ápices e septadas. As paráfises de $R$. lonchocarpi têm paredes grossas ou sólidas,
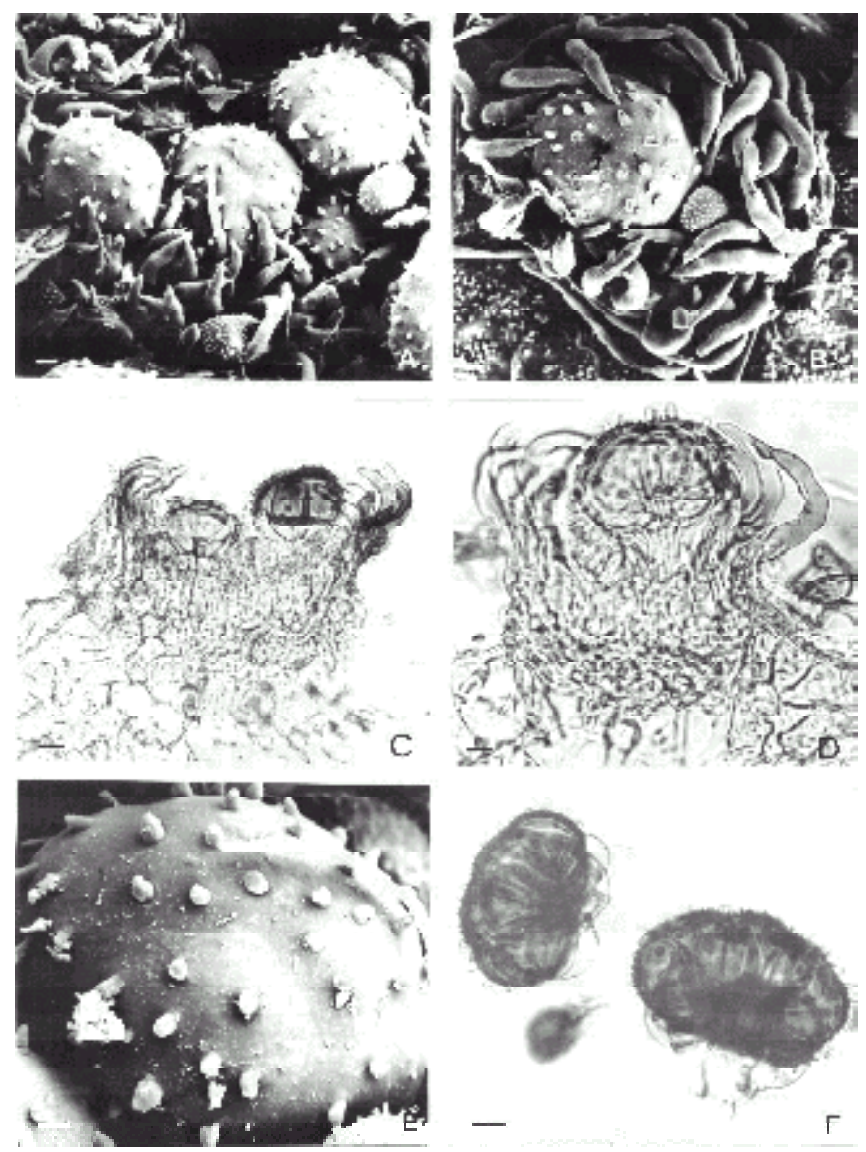

FIG. 7 - A - F. Ravenelia lonchocarpi sobre Lonchocarpus campestris. A e B - Télios subepidérmicos vistos ao MEV mostrando paráfises periféricas, teliósporos com ornamentos tuberculóides e urediniósporo equinulado. C e D - Cortes de télios vistos ao MO, contendo paráfises e teliósporos compostos. E - Teliósporo tuberculado visto ao MEV. F - Teliósporos visto ao MO, mostrando superfície tuberculada e cistos aderentes. Barras: A, B, D e F $=10 \mu \mathrm{m} ; \mathbf{C}=20 \mu \mathrm{m} ; \mathbf{E}=\mathbf{5} \mu \mathrm{m}$. 
Revisão taxonômica de espécies de Ravenelia em leguminosas do cerrado brasileiro

pontudas e não septadas. Além disso, no recente estudo observou-se que as células que formam as paráfises são arredondadas, pequenas e unidas. Ravenelia lonchocarpi parece ser limitada à América do Sul, sendo comum no Brasil e Equador (Joerstad, 1959; Baxter, 1968). Joerstad (1959) observou que os télios de $R$. lonchocarpi são freqüentemente pequenos e, em muitos casos, contêm um único teliósporo protegido por paráfises encurvadas abundantes. Ao MEV, confirmou-se que os teliósporos são produzidos, um a um e liberados de dentro dos pequenos télios, mas ocorre também a produção simultânea de vários teliósporos por télio.

Baxter (1968) relatou que os urediniósporos têm dois - três poros germinativos indistintos. Comprovou-se aqui que os urediniósporos têm de dois - quatro poros germinativos, a maioria três, os quais são nítidos, equatoriais ou subequatoriais com um dos poros germinativos sempre na parte lisa do esporo.

\section{Ravenelia mimosae-sensitivae P. Henn. Hedwigia 35:246. 1896}

Sinonímias: Ravenelia mimosae-albidae Diet. Bot. Centralb. (Beith.) 20:378. 1906; Ravenelia mimosaecaeruleae Diet. 20:378. 1906; Ravenelia mimosicola Arth. N. Amer. Flora 7:137. 1907; Ravenelia victoria-rossetii Dianese, Santos, Medeiros \& Sanchez. Fitop. Bras. 18:442. 1993.

Espermogônios e écios não vistos. Urédios anfígenos, (56-) 151 (-216) x (27-) 50 (-89) $\mu \mathrm{m}$, maioria epífilo, subcuticulares na origem, irrompentes, amarelo-ferrugíneos, parafisados. Paráfises himeniais, cilíndricas, com ápices clavados a ovóides com 55 x $10 \mu \mathrm{m}$ e $4 \mu \mathrm{m}$ de diâmetro na haste, coloridas e levemente curvadas. Urediniósporos (14-) 16 (-19) x (14-) 16 (-17) $\mu \mathrm{m}$, globóides a obovóides, densamente equinulados; equinulações aciculares, formando retículos quando vistos em $\mathrm{MEV}$ inclusive com nervuras formando triângulos; paredes (1-) 1,5 (-2,5) $\mu \mathrm{m}$ de espessura; poros germinativos quatro - nove, geralmente nove. Télios (65-) 84 (-91) x (30-) 30 (-32) $\mu \mathrm{m}$, mistos, anfígenos, marromescuros. Teliósporos compostos, (67-) 77 (-84) x (65-) 71 (79) $\mu \mathrm{m}$, pedicelados, com quatro - cinco células centrais (20-) 25 (-30 x (17-) 21 (-24) $\mu \mathrm{m}$, escuras, ornamentadas com três a dez tubérculos em cada célula; tubérculos irregulares, espaçados, em forma de cones ou pequenas verrugas, (4-) 5 (-7) x (2,5-) $3(-4) \mu \mathrm{m}$; células marginais (30-) $32(-38) \times$ (16-) $22(-25) \mu \mathrm{m}$, tuberculares, semelhantes às células centrais. Cistos seis - oito, geralmente oito, globóides, higroscópicos, pendentes, multisseriados, (10-) 15 (-16) $\mu \mathrm{m}$. Pedicelos compostos, hifálicos, decíduos.

Espécimes examinados: em folhas vivas de Mimosa radula var. imbricata Benth.: Estação Experimental de Biologia, Universidade de Brasília, Brasília, DF, 23/IV/1993, R.B. Medeiros 227, UB 3299; Estação Experimental de Biologia, Universidade de Brasília, Brasília, DF, 12/III/1993, J.F. Hennen 3, UB 3373.

Das espécies de Ravenelia ocorrendo em Mimosa spp., descritas por Sydow \& Sydow (1915), seis apresentam soros subcuticulares, ornamentações nos teliósporos e paráfises globóides ou clavadas. Somadas a estas características, as equinulações dos urediniósporos são muito próximas e simétricas, característica comum em várias espécies de Ravenelia que infetam espécies de Mimosa. Por exemplo, Ravenelia mimosae-sensitivae P. Henn., Ravenelia mimosaealbidae Diet., Ravenelia mimosae-caeruleae Diet., Ravenelia fragrans Long. e Ravenelia mimosicola Arth. foram estudadas e ilustradas por Cummins (1978) e consideradas como sinonímias de $R$. mimosae-sensitivae. Ravenelia victoriarossetii Dianese, Santos, Medeiros \& Sanchez é sinônimo de $R$. mimosae-sensitivae por questão de prioridade definida pelo Código Internacional de Botânica (Greuter et al. 1994). Ravenelia verrucata Cumm. \& Baxt. (Cummins \& Baxter, 1975), descrita em Mimosa spp., apresenta urediniósporos com a ornamentação semelhante às de $R$. mimosae-sensitivae e verrugas espaçadas nos teliósporos, no entanto possui dimensões dos esporos significativamente maiores que esta. As espécies $R$. fragrans var. fragrans Long. var. fragans e $R$. fragrans Long. var. evernia (Syd.) J.W. Baxt., se diferenciam de $R$. mimosae-sensitivae pois apresentam dimensões muito maiores dos urediniósporos, diferenças na ornamentação dos teliósporos e número de cistos. Outras espécies que ocorrem em Mimosa spp. como R. idonea H.S. Jack., R. bahiensis P. Henn. e $R$. septata Henn. \& Cumm. não se assemelham a $R$. mimosae-sensitivae, sendo, portanto, definitivamente diferentes desta espécie. Em síntese, ambos os materiais examinados pertencem à espécie $R$. mimosae-sensitivae.

7. Ravenelia pileolarioides H. Syd. \& P. Syd. Ann. Mycol. 14:68. 1916. (Figuras 8-9)

Sinonímia: Ravenelia paraybana Viégas. Bragantia 5:54. 1945.

Espermogônios e écios não vistos. Urédios anfígenos, subepidérmicos, irrompentes, maioria hipófilo, pequenos, (10-) 20 (-38) x (5-) $12(-12) \mu \mathrm{m}$, com aparência de uma cesta, pela presença abundante de paráfises periféricas e curvadas, amareladas, (38-) 45 (-100) $\mu \mathrm{m} \times 6-10 \mu \mathrm{m}$ de diâmetro, unidas nas bases, oriundas de células arredondadas. Urediniósporos (20-) 23 (-27) x (13-) 15 (-18) $\mu \mathrm{m}$, ovóides, oblongos a elipsóides, quatro - seis poros germinativos, equatoriais ou subequatoriais; parede lateral 1,5-3 $\mu \mathrm{m}$ de espessura e $5-10 \mu \mathrm{m}$ no ápice, em geral $7 \mu \mathrm{m}$ de espessura, dourado-ferrugínios a amarronzados; estrias verrugosas helicoidais, paralelas, conspícuas, $1-2,5 \mu \mathrm{m}$ de largura. Télios anfígenos, mistos, subepidérmicos, irrompentes, maioria hipófilo, parafisados. Paráfises $41-100$ x $8-12 \mu \mathrm{m}$. Teliósporos compostos, pedicelados, (70-) 78 (-96) x (50-) $70(-85) \mu \mathrm{m}$, poucos por télia, envolvidos por uma membrana transparente vista como resíduo preso à margem dos esporos, verrugosos; verrugas globóides, $1-4 \mu \mathrm{m}$, hialinas ou pigmentadas, 5 - 6 células diametralmente dispostas; quatro células centrais, (19-) 21 (-22) x (16-) 19 (-20) $\mu \mathrm{m}$, tuberculares; células marginais, (22-) 23 (-25) x (14-) 16 (20) $\mu \mathrm{m}$, seis - oito tubérculos por célula. Cistos hialinos, seis - oito, higroscópicos, aderentes, 20 - $22 \mu \mathrm{m}$ de diâmetro. Pedicelos decíduos, hifálicos, hialinos, compostos, (5-) 8 (- 
10) $\mu \mathrm{m}$ de comprimento, ornamentados por pequenas verrugosidades.

Espécimes examinados: em folhas vivas de Caesalpinia pyramidalis Tulasne: a $13 \mathrm{~km}$ do Rio Balsas, Loreto, MA, 09/IV/1995, J. C. Dianese 2214, UB 2191.

A espécie $R$. pileolarioides foi descrita sobre Pithecellobium sp. coletado no Ceará (Sydow \& Sydow, 1916). Viégas (1945) descreveu a espécie como $R$. paraybana Viégas sobre Caesalpinia sp. (catingueiro), coletada por J. Deslandes na Paraíba em 1938 . Entretanto, $R$. paraybana foi colocada em sinonímia de $R$. pileolarioides por Baxter (1975), que estudou o fungo em Pithecellobium sp., também coletado no Ceará em 1910.

As características morfológicas encontradas no espécime examinado correspondem à descrição de $R$.
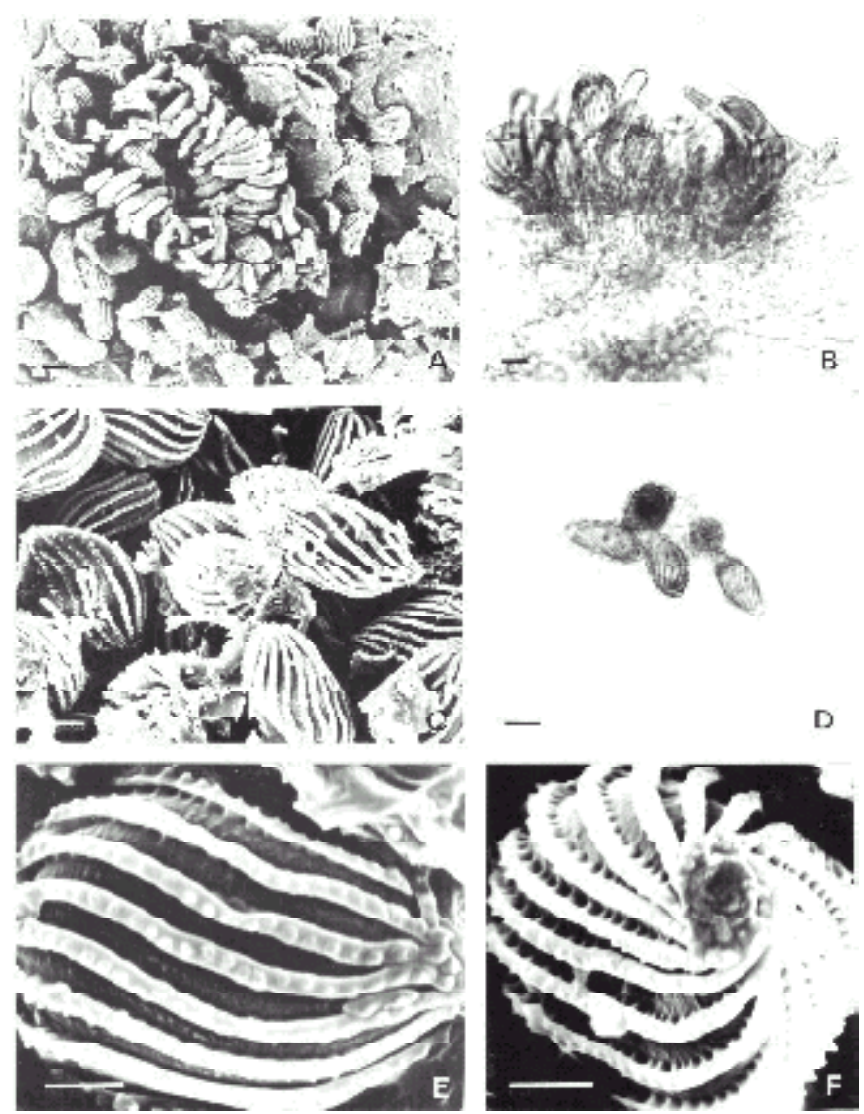

FIG. 8 - A - F. Ravenelia pileolarioides sobre Caesalpinia pyramidalis. A - Urédio subepidérmico irrompente visto ao MEV mostrando paráfises periféricas recurvadas formando uma cesta. B - Corte de urédio visto ao MO com paráfises recurvadas e urediniósporos estriados. C - Urediniósporos vistos ao MEV. D - Urediniósporos vistos ao MO, mostrando estrias e poros germinativos. $\mathbf{E}$ e $\mathbf{F}$ Detalhes das estrias salientes e verrugosas dos urediniósporos ao MEV mostrando a porção basal de um urediniósporo para onde as estrias se convergem. Barras: A, B e D = $10 \mu \mathrm{m} ; \mathrm{C}, \mathrm{E}$ e F = $5 \mu \mathbf{m}$. pileolarioides (Sydow \& Sydow, 1916; Viégas, 1945; Baxter, 1975). Os urediniósporos desta espécie são típicos por apresentarem estrias verrugosas. Ambos urédios e télios são anfígenos, subepidérmicos, protegidos por paráfises muito curvadas unidas nas bases, formando estrutura semelhante à uma cesta. $\mathrm{O}$ hospedeiro estudado, Caesalpinia pyramidales Tul., tem ampla distribuição na Bahia, Maranhão e por todo o Ceará, onde é conhecida popularmente por catingueiro-deporco, pau-de-rato, catingueiro e mussitaíba (Lewis, 1987).

Mais quatro espécies de Ravenelia formam urediniósporos com superfície ornada por estrias salientes, R. striatispora Cumm. \& Baxter (Baxter, 1975) R. corbula Baxter (Baxter, 1966), R. corbuloides Hennen \& Cumm. e $R$. spiralis Hennen \& Cumm. (Hennen \& Cummins, 1990).. Ravenelia striatispora apresenta estrias longitudinais, ligadas
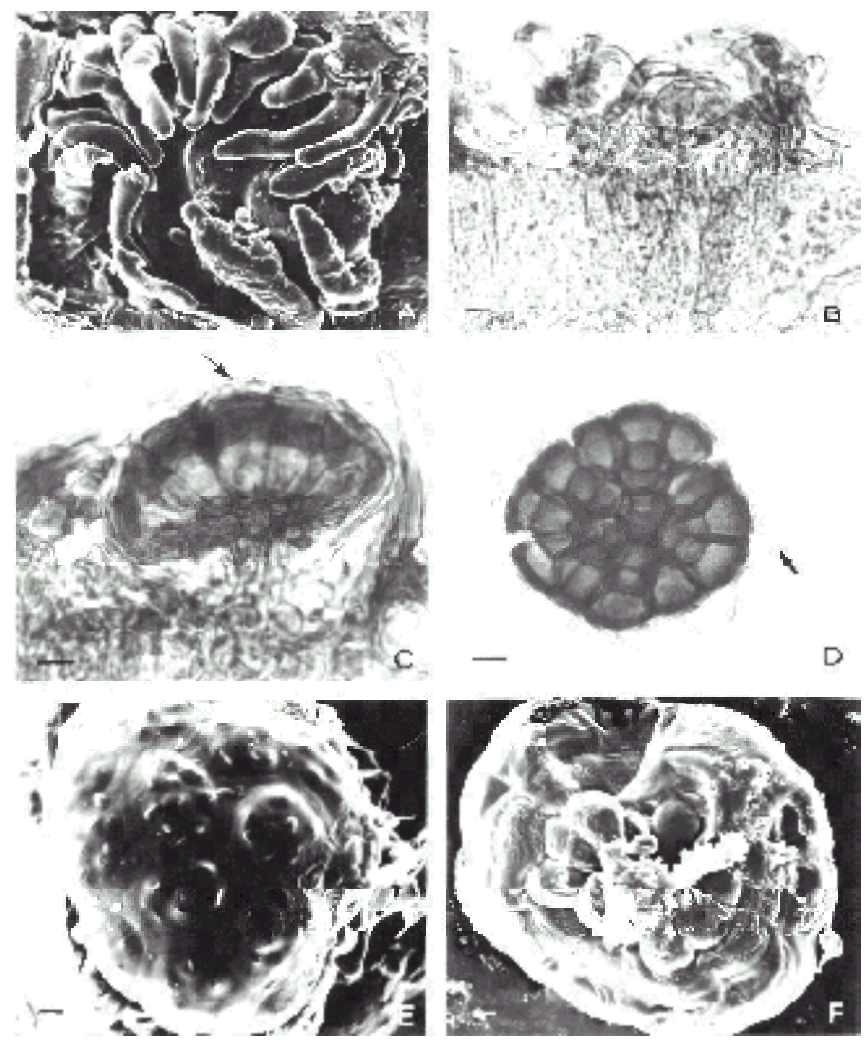

FIG. 9 - A - F. Ravenelia pileolarioides sobre Caesalpinia pyramidalis. A - Télio visto ao MEV com um teliósporo parcialmente recoberto por paráfises curvadas. B e C - Cortes transversais de télios subepidérmicos ao MO mostrando em C a superfície com verrugas espessas aparecendo como ondulações, bem como, mostrando membrana hialina superficial (seta). D - Teliósporo composto mostrando células centrais, células marginais e restos de membrana hialina envolvendo o esporo (seta). E - Teliósporo visto ao MEV, mostrando verrugas na superfície adaxial. F - Cistos na parte basal de um teliósporo composto ao MEV. Barras: A, C e D = $10 \mu \mathrm{m} ; \mathrm{B}=20 \mu \mathrm{m}$; E e $\mathbf{F}=\mathbf{5} \mu \mathbf{m}$. 
Revisão taxonômica de espécies de Ravenelia em leguminosas do cerrado brasileiro

umas às outras transversalmente nos urediniósporos, paráfises ausentes nos urédios, teliósporos são encontrados nos urédios, e são muito maiores, lisos, com número de células centrais, marginais e de cistos diferentes dos de $R$. pileolarioides. Além disso, possui outro hospedeiro, Pithecelobium mexicanum Rose, com ocorrência no México. Ravenelia corbula apresenta écios com paráfises menores do que os dos urédios e eciósporos maiores do que os urediniósporos, mas ambos estriados. Os esporos de $R$. corbula são maiores do que as de $R$. pileolarioides, com paredes mais finas e, em geral, com quatro poros germinativos, além dos urédios e télios serem abaxiais, subcuticulares, com paráfises mais longas e mais espessas. Os teliósporos de $R$. corbula, além de maiores, apresentam número de células diferentes, equinulações cônicas de até 16 $\mu \mathrm{m}$ nas células marginais, ocorrendo também em hospedeiro diferente, $C$. eriostachya Benth., encontrada no México. A terceira espécie $R$. corbuloides apresenta urédios subcuticulares com paráfises com até $40 \mu \mathrm{m}$ de comprimento, urediniósporos estriados com dimensões e poros germinativos diferentes dos de $R$. pileolarioides. Porém, a maior diferença está nos télios de $R$. corbuloides que são hipófilos, inicialmente sem paráfises e nos teliósporos que são muito grandes e totalmente lisos, embora as dimensões das células centrais sejam próximas dos de $R$. pileolarioides. Hennen \& Cummins (1990) descreveram $R$. corbuloides sobre Caesalpinia bracteosa Tulasne e C. pyramidalis. Ravenelia pileolarioides é aqui relatada em $C$. pyramidalis. Com base nos dados aqui mostrados sugere-se o estudo do espécimentipo de $R$. corbuloides para se verificar se não se trata também de $R$. pileolarioides. A quarta espécie com urediniósporos estriados, também descrita por Hennen \& Cummins (1990), é $R$. spiralis que tem como hospedeira Cenostigma sp. e $C$. macrophylla Tul., com urédios mistos hipófilos, paráfises com a mesma dimensão daquelas em $R$. pileolarioides, urediniósporos semelhantes, porém com poros germinativos diferentes pois são localizados próximos ao hilo. Além disso, os teliósporos são menores, lisos, com células centrais menores e em menor número do que $R$. pileolarioides e $R$. corbuloides. A ontogenia de paráfises mostra que o tamanho delas varia muito desde o seu início até a maturidade. Portanto, o tamanho de paráfises tem que ser visto com cuidado.

8. Ravenelia santos-costae Dianese, Med., Santos, Furlan., Sanchez \& A.C. Dianese. Fitop. Bras. 18:443444. 1993.

Espermogônios e écios não vistos. Urédios (196-) 206 (-278) x (49-) 59 (-78) $\mu \mathrm{m}$, anfígenos, subcuticulares, irrompentes, laranja-dourados, parafisados. Paráfises (68-) $82(-100) \times(4-) 4,5(-6) \mu \mathrm{m}$, himeniais e periféricas com ápices elípticos, globóides ou ovóides, (14-) 19 (-25) $\mu \mathrm{m}$ de diâmetro. Urediniósporos (23-) 27 (-32) x (16-) 20 (-23) $\mu \mathrm{m}$, amarelados, equinulados; paredes 1,5-2 $\mu \mathrm{m}$ de espessura, dois - seis poros germinativos equatoriais, em geral seis, bizonados. Télios (392-) 452 (-588) x (39-) 57 (-84) $\mu \mathrm{m}$, anfígenos, em geral hipófilos, subcuticulares, irrompentes, marrom-escuros, raramente parafisados. Teliósporos (53-) 56
(-64) x (51-) 56 (-61) $\mu \mathrm{m}$, compostos, multicelulares, quatro células centrais equinuladas, dez - 16 espículos por célula; células marginais (24-) $27(-34)$ x (20-) $24(-30) \mu \mathrm{m}$, paredes $3-5 \mu \mathrm{m}$ de espessura, equinuladas. Cistos (18-) $20(-22) \mathrm{x}$ (18-) 20 (-22) $\mu \mathrm{m}$, com projeções papiladas, em número de seis, globóides. Pedicelos compostos hifálicos, duas - quatro hifas unidas.

Espécimes examinados: em folhas vivas de Calliandra dysantha Benth.: SHIN QI 4, Conj. 6 lote 1, Lago Norte, Brasília, DF; 16/VIII/1992; J.C. Dianese 402, UB 1495; 07/ IX/1992; J.C. Dianese 485, UB 1838; 10/V/1997; J.C. Dianese 3266, UB 15001.

Os urédios e télios são anfígenos, ao contrário da descrição original onde estes foram considerados hipófilos e epífilos, respectivamente (Dianese et al., 1993). Além disso, as paráfises estão sempre associadas aos urédios e não aos télios e os urediniósporos apresentam quatro a seis poros germinativos bizonados, geralmente seis e não dois a quatro poros germinativos conforme Dianese et al. (1993). A presença de nervuras em torno das células dos teliósporos é facilmente vista ao MEV. A presença de verrugas nos cistos é uma característica adicional para esta espécie, não tendo sido observada em nenhuma outra aqui estudada.

Entre as espécies de Ravenelia em Calliandra spp. no Brasil, as que possuem teliósporos ornamentados são $R$. pazschkeana Diet. e $R$. armata Syd. Considerando a descrição original, a espécie $R$. santos-costae ficaria em sinonímia com $R$. pazschkeana relatada sobre Calliandra sp. porque quase todas as características e dimensões de esporos estão de acordo com aquelas de $R$. pazschkeana. Entretanto, como $R$. santoscostae apresenta urédios e télios anfígenos e ambos subcuticulares, pode assim ser separada de $R$. pazschkeana que forma télios e urédios epífilos na maioria e subepidérmicos. As equinulações nos teliósporos variam de dez - 16 por célula em $R$. santos-costae e de seis - dez em $R$. pazschkeana. A presença de verrugas nos cistos é outra característica de $R$. santos-costae, ausente na descrição de $R$. pazschkeana sendo porém facilmente vista ao MEV em $R$. santos-costae.

Já na descrição de $R$. armata, télios não foram mostrados, mencionando-se a presença de teliósporos em urédios, aparafisados e os urediniósporos e teliósporos eram muito maiores do que em $R$. santos-costae. Embora o número de células centrais e marginais seja igual, estas apresentam verrugas hialinas pequenas e não grandes equinulações, como em $R$. santos-costae.

\section{REFERÊNCIAS BIBLIOGRAFIAS}

ARTHUR, J.C. Order Uredinales. North American Flora 7:669-732. 1925

ARTHUR, J.C. Manual of the rusts in United States and Canada. Purdue Research Foundation. Lafayette. 1934.

BAXTER, J.W. New species of rust fungi from Mexico. Mycologia 58:336-338. 1966.

BAXTER, J.W. The species of Ravenelia occurring on 


\section{D.V. Rezende \& J.C. Dianese}

Lonchocarpus. Mycologia 60:42-48. 1968.

BAXTER, J.W. Notes on Brazilian species of Ravenelia. Mycologia 67:436-437. 1975.

BRUZESSE, E. \& HASAN, S. A whole leaf clearing and staining technique for host specificity studies of rust fungi. Plant Pathology 32:335-338. 1983.

CUMMINS, G.B. Rust Fungi on Legumes and Composites in North America. Tucson, AZ: Univ. Arizona Press. 1978.

CUMMINS, G.B. \& BAXTER, J.W. Two nomenclatural changes in Ravenelia. Mycologia 67:1042-1043. 1975.

DIANESE,J.C., MEDEIROS, R. B., SANTOS, L.T.P., FURLANETO, C., SANCHEZ, M. \& DIANESE, A.C. Batistopora gen. Nov. and new Phakopsora, Ravenelia, Cerotelium, and Skierka species from the Brasilian Cerrado. Fitopatologia Brasileira 18:436450. 1993.

DIETEL, P. Die Gattung Ravenelia. Hedwigia 33:22-69. 1894.

GREUTER, W., BARRIE, F.R., BURDET, H.M., CHALONER, W.G., DEMOULIN, V., HAWKSWORTH, D.L., JORGENSEN, P.M., NICOLSON, D.H., SILVA, P.C. \& TREHANE, P. International Code of Botanical Nomenclature (Tokyo Code). Koeltz Scientific Books. Königstein. 1994.

HENNEN, J.F. \& CUMMINS, G.B. New species and nomenclature of Ravenelia in Neotropica. Reporter Tottori Mycological Institute 28:1-14. 1990.

HENNINGS, P. Fungi blumenavienses, a cl. Alfr. Moller Lecti.
Hedwigia 34:335-558. 1895.

JACKSON, H.S. The rusts o South America based on the Holway Collections III. Mycologia 23:96-116. 1931.

JOERSTAD, I. Uredinales from South America and tropical North America, chiefly collected by Swedish botanists II. Ark. Bot. Ser. 2:49-103. 1959.

LEWIS, G.P. Legumes of Bahia. Royal Botanic Garden Kew. London. 1987.

LINDQUIST, J.C. Três especies nuevas o criticas de Ravenelias argentinas. Buletin de la Sociedad Argentina de Botânica 4:298302. 1946.

LINDQUIST, J.C. \& COSTA NETO. Uredinales do Rio Grande do Sul (Brasil). Rev. de la Facultad de Agronomia, Universidad Nacional de la Plata 39:111-153. 1963.

SILVEIRA, V.D. Elementos de fitopatologia. Agronomia 10:1-44. 1951.

SOUZA,W. de. Técnicas básicas de microscopia eletrônica aplicadas às ciências biológicas. Rio de Janeiro. Sociedade Brasileira de Microscopia. 1998.

SYDOW, P. \& SYDOW, H. Monografia Uredinearum vol. 3. Fratres Borntraeger. Leipsig. 1915.

SYDOW, P. \& SYDOW, H. Fungi amazonici a cl. E. Ule lecti. Annales Mycoloy 14:65-97. 1916.

VIÉGAS, A. P. Uns poucos fungos do Brasil. Bragantia 5:561-582. 1945. 